\title{
Effect of Gelatin-Based Edible Coatings Incorporated with Aloe vera and Black and Green Tea Extracts on the Shelf Life of Fresh-Cut Oranges
}

\author{
Mohsen Radi, ${ }^{1,2}$ Elham Firouzi, ${ }^{2}$ Hamidreza Akhavan, ${ }^{3}$ and Sedigheh Amiri ${ }^{1,2}$ \\ ${ }^{1}$ Young Researchers and Elite Club, Yasooj Branch, Islamic Azad University, Yasooj, Iran \\ ${ }^{2}$ Department of Food Science and Technology, Yasooj Branch, Islamic Azad University, Yasooj, Iran \\ ${ }^{3}$ Department of Food Science and Technology, Faculty of Agriculture, Shahid Bahonar University of Kerman, Kerman, Iran \\ Correspondence should be addressed to Sedigheh Amiri; sedighehamiri@gmail.com
}

Received 30 June 2016; Accepted 25 August 2016; Published 9 January 2017

Academic Editor: María B. Pérez-Gago

Copyright ( 2017 Mohsen Radi et al. This is an open access article distributed under the Creative Commons Attribution License, which permits unrestricted use, distribution, and reproduction in any medium, provided the original work is properly cited.

\begin{abstract}
The aim of this study was to evaluate the effect of gelatin coating incorporated with Aloe vera gel $(50,100 \%)$ and green and black tea extracts $(5,10 \%)$ on physicochemical, microbial, and sensorial properties of fresh-cut oranges at $4^{\circ} \mathrm{C}$ for 17 days. Significant differences in terms of quality parameters were observed between the control and coated fresh-cut oranges. The highest variation of quality parameters was observed in control, while the least variations were observed in coated slices with $100 \%$ Aloe vera and $10 \%$ green tea extract. The weight loss was increased with time, but the coating treatment especially with $100 \%$ Aloe vera had significant effect on the prevention of weight loss. Also, Aloe vera coated samples obtained the highest score in sensory evaluation. Coating with gelatin incorporated with Aloe vera and green tea extracts successfully retarded the microbial growth and therefore extended the shelf life of fresh-cut oranges during cold storage.
\end{abstract}

\section{Introduction}

Citrus fruits have a high commercial value in the fruit market. Among them, oranges can be considered as a good source of bioactive compounds, in which their consumption would have health benefits for humans [1]. However, high moisture content and nutrient composition make this fruit more susceptible to fungi contamination [2]. It should be noted that such products are also susceptible to softening, browning, or color change and microbial contaminations, too [3]. On the other hand, peeling, cutting, or slicing increases the quality losses of fresh-cut fruits. Therefore, controlling fresh quality and growth of spoilage and pathogenic bacteria is a challenging problem for fresh-cut fruit industry [4]; and although nutrient loss could occur, preservative treatment for fresh-cut fruit is recommended.

In order to overcome the above concerns, it is recommended to use edible coatings on fresh-cut fruits to extend their shelf life. For this purpose, natural polysaccharides, proteins, and antioxidants are used as raw materials for edible coatings and films [3]. Edible coatings are thin layers of edible materials that cover the surface of food by dipping or spraying and providing a barrier to gases and water vapor and somewhere are microbial agents and therefore reduce respiration, enzymatic browning, water loss, and deleterious microbial effects [5].

Tea (Camellia sinensis) is a good source of polyphenolic compounds, which have strong antioxidant properties. Green tea and black tea differ primarily in their processing and relative levels of catechins and their oxidized condensation products. The high antioxidant capacity and overall antimicrobial activity of green tea have been attributed to these compounds $[6,7]$. Such properties made us use black tea and green tea as our alternatives for coating.

Also, Aloe vera gel and gelatin have been used as edible coatings in fruit storage technology $[8,9]$. The colorless mucilaginous gel of Aloe vera, consisting of approximately $99-99.5 \%$ water and $0.5-1 \%$ solid materials, includes compounds such as polysaccharides, vitamins, minerals, enzymes, phenolic compounds, and organic acids [10]. The 
barrier properties of Aloe vera gel coatings towards respiratory gases [11], as well as its antimicrobial functions [12], were reported in coated fruits and fresh-cut fruits.

In recent years, Aloe vera gel has been used as an edible coating for nectarines [13], sweet cherries [12], mangoes [8], apples [11, 14], papayas [15], table grapes [16], and fresh-cut kiwifruit $[17,18]$.

Although the effects of various edible coatings on freshcut fruits and vegetables have been reported by several authors, no information is available about coating of orange slices with gelatin in combination with Aloe vera and green tea and black tea extracts. Therefore, the current research was established to investigate the effect of basic edible coating (gelatin) in combination with two concentrations of Aloe vera gel and green tea and black tea extracts on the physicochemical and microbial characteristics of orange slices during storage.

\section{Materials and Methods}

2.1. Materials. Gelatin, 2,6-dichlorophenolindophenol, phenolphthalein, $\mathrm{NaOH}, \mathrm{NaCl}$, microbial culture media of plate count agar (PCA), and yeast extract glucose chloramphenicol (YGC) agar were purchased from Merck (Darmstadt, Germany). Orange fruits (at commercial maturity), Aloe vera leaves, and dried leaves of green tea and black tea were purchased from a local wholesale market (Yasouj, Iran).

\subsection{Preparation of the Coating-Forming Solutions. Aloe vera} extract was obtained from fresh aloe leaves according to the method described by Navarro et al. [19] and used intactly (for Aloe vera 100\% treatment) or diluted 50:50 with distilled water (for Aloe vera $50 \%$ treatment) to form half concentration extract. Moreover, green tea and black tea extracts were prepared from dried tea leaves based on the method of Siripatrawan and Harte [20]. Briefly, the mixture of ground tea powders and distilled water $(1: 10 \mathrm{w} / \mathrm{w})$ was stirred in an Erlenmeyer flask in a shaking water bath (Memmert, Germany) at $80^{\circ} \mathrm{C}$ and 100 oscillations/min for $10 \mathrm{~min}$. Afterwards, the tea extracts were filtered through Whatman number 1 filter paper. A part of tea extracts (about $10 \mathrm{~g}$ ) for total soluble solid content were examined by air oven method at $105^{\circ} \mathrm{C}$ and, according to total solid content (TSC), the final concentrations of extracts were adjusted to $5 \%$ and $10 \%$ TSC using a Rotary evaporator (Heidolph, Germany) at $45^{\circ} \mathrm{C}$. Gelatin powder was dissolved in distilled water or concentration-adjusted Aloe vera and tea extracts by stirring and heating to $50^{\circ} \mathrm{C}$ under nitrogen gas atmosphere to form $1 \%$ gelatin solution.

2.3. Coating the Orange Slices. Oranges with uniform size and shape and without any signs of mechanical damage were selected, washed with chlorinated water $\left(50 \mathrm{mgCl}_{2} / \mathrm{kg} \mathrm{H}_{2} \mathrm{O}\right)$, and finally sliced. Orange slices were dipped in the coating solutions for $1 \mathrm{~min}$ and then drained for $30 \mathrm{~min}$. Some slices were dipped in distilled water as control samples. The prepared slices were packed in polyethylene terephthalate (PET) clamshells $\left(140 \times 128 \times 30 \mathrm{~mm}^{3}\right)($ Pars Plastic Khuzestan,
Ahwaz, Iran) with four vent holes (1 $\mathrm{mm}$ in diameter) and stored at $4^{\circ} \mathrm{C}$ for 17 days. Subsequently, the following coating treatments were assigned: uncoated sample which served as control, orange slices coated with $1 \%$ gelatin, orange slices coated with $1 \%$ gelatin in combination with $50 \%$ and $100 \%$ Aloe vera gel, and $5 \%$ and $10 \%$ green tea and black tea extracts. 10 orange slices were placed in one container and three replicates were considered for each treatment on one day. The physicochemical analyses of samples were performed at 0,5 , 9,13 , and 17 days of storage.

2.4. Weight Loss Determination. The weight loss in the samples was calculated as loss in weight of the orange slices in each container during storage and the values were reported on a percentage basis [14] and calculated by the following formula:

$$
\begin{aligned}
& \text { weight loss } \% \\
& =\frac{(\text { Initial weight }- \text { weight in the specific time of storage })}{\text { initial weight }} \\
& \quad \times 100 .
\end{aligned}
$$

2.5. Measurement of Total Soluble Solids (TSS), Titratable Acidity (TA), $p H$, and Ascorbic Acid (AA) Content. The orange slices were homogenized in a blender (Moulinex, Barcelona, Spain) and the blended puree was used to determine the total soluble solid (TSS), titratable acidity (TA), $\mathrm{pH}$, and ascorbic acid content. The homogenate was centrifuged at $2000 \mathrm{rpm}$ for $1 \mathrm{~min}$ to obtain a clear juice. TSS was determined with a refractometer (Atago NAR-3T, Tokyo, Japan) at $20^{\circ} \mathrm{C}$ and expressed in ${ }^{\circ} \mathrm{Bx}$. TA values were determined by diluting each $10 \mathrm{~mL}$ aliquot of homogenized orange juice in $50 \mathrm{~mL}$ of distilled water and then titrated to $\mathrm{pH} 8.1$ (Knick pH meter 766 , Germany) by using $0.1 \mathrm{M} \mathrm{NaOH}$. The TA results were expressed as grams of citric acid per $100 \mathrm{~mL}$ orange juice. Also, the ascorbic acid content was measured using a titration method with 2,6-dichlorophenolindophenol [17].

2.6. Measurement of Visual Color. Surface color of the samples was measured using a Hunter colorimeter (ColorFlex, Virginia, USA). Hunter CIE $L^{*}$ for lightness, $a^{*}$ for redness, and $b^{*}$ for yellowness were determined [17].

2.7. Microbiological Evaluation. The microbiological analyses of orange slices were carried out for total aerobic mesophilic bacteria and fungi counts in accordance with Benítez et al. [18]. Results were expressed as log CFU/g of sample.

2.8. Sensory Analysis. Sensory evaluation was performed immediately after the orange slices were removed from storage conditions. 12 untrained panelists $(6$ males and 6 females aged between 20 and 45 years) were responsible for sensory evaluation using a 5-point scale. The members were asked about the different quality attributes (color, aroma, flavor, and overall acceptance) of the orange slices using a hedonic scale from extremely dislike (1) to extremely like (5). Water and unsalted crackers were used in assessing the 
samples as palate cleansers. The rest time between tests was 1 minute.

2.9. Statistical Analysis. All experiments were run in triplicate. Statistics on a completely randomized design were performed with the analysis of variance (ANOVA) procedure in SAS (release 9.1, SAS Institute Inc., Cary, NC) software and mean comparisons were carried out by Duncan's multiple range test $(p<0.05)$.

\section{Results and Discussion}

3.1. Total Soluble Solids (TSS), Titratable Acidity (TA), and $p H$. The effects of coating treatments on $\mathrm{pH}, \mathrm{TA}$, and TSS parameters during cold storage were shown in Figures 1(a)-1(c). pH was increased significantly in all treatments during storage. The lowest increase $(0.9 \%)$ in $\mathrm{pH}$ was observed in coated sample with $1 \%$ gelatin. In contrast, the maximum increase ( 16\%) was observed in samples coated with $100 \%$ Aloe vera and 5 and $10 \%$ green tea extracts. A significant increase in $\mathrm{pH}$ was also reported for green tea and chlorine treatments of fresh-cut lettuce. This $\mathrm{pH}$ increase was contributed to the growth of Gram-negative microorganisms, which play an important role in the spoilage of fresh-cut lettuce [7].

The acidity of the coated and control samples significantly reduced at different rates during the storage $(p<0.05)$. Initial acidity of samples was approximately $0.78 \mathrm{~g} / 100 \mathrm{~mL}$. The decreasing trend of TA in the coated samples with $100 \%$ Aloe vera and also $10 \%$ green tea extract was the highest (38-40\%). In contrast, this trend for samples coated with $1 \%$ gelatin was the lowest ( 14\%). Similar trends for $\mathrm{pH}$ and TA were also reported for fresh-cut kiwifruit [18].

The TSS of control and coated samples significantly increased with storage time. In this regard, there was a significant difference between control and coated samples, as coated samples experienced a slight increase in TSS when compared to control. The highest increase of TSS was observed in control (32.40\%, TSS increased from 11.9 to 15.85 after 17 days of storage at $4^{\circ} \mathrm{C}$ ), while the lowest increase was observed in samples coated with $50 \%$ and $100 \%$ Aloe vera extract ( 13.0\%, TSS increased from 12.0 to 13.49 and 13.70 , resp.).

The findings of this study were similar to the results of Ahmed et al. [13] and Marpudi et al. [15] who reported that TA decreased and TSS increased with increasing storage time in nectarines and papaya, respectively. Conversely, Song et al. [14] declared that the storage period did not affect the TSS of gel-coated apple slices. This result was confirmed by Bett et al. [21], too. However, Saftner et al. [22] reported that the TA decreased but TSS did not change with increasing storage time in apple slices.

Generally, it is declared that the edible coating can decrease gas permeability in slices' surface leading to a decrease in respiration rate, which could be responsible for the lower change in TSS and TA in coated slices $[12,14,18$, 21]. It is reported that, during ripening, organic acids are used as substrates in respiration metabolism, and thereby TA would be decreased and $\mathrm{pH}$ and TSS would be increased.
In general, it seems that total soluble solid content tends to increase over the storage period as a consequence of ripening process $[18,23]$. Respiration metabolism in fruit tissues entails a progressive decrease in $\mathrm{O}_{2}$ and increase in $\mathrm{CO}_{2}$ over time under all packaging conditions [18]. The reduction of respiration rate has been observed in sweet cherry [12] and kiwifruit [18] coated with Aloe vera gel.

Titratable acidity and $\mathrm{pH}$ variations of green tea coated samples were higher than other samples followed by Aloe vera coated slices (Figures 1(b) and 1(c)). However, higher acidity of control and coated samples with gelatin in this study might be contributed to higher microbial population and therefore acid production by microbial flora in these samples (6.44 log CFU/g for control, Figure 3). On the other hand, the lower microbial counts of coatings containing antimicrobial agents such as green tea or Aloe vera extracts resulted in lower acid production and therefore lower acidity in these samples.

3.2. Weight Loss. The weight loss is mainly associated with moisture evaporation through the surface of fruit slices [24]. The rate of water loss depends on the water pressure gradient between the fruit tissue and the surrounding atmosphere and the storage temperature. Thus, the slicing of fruits makes them susceptible to rapid water loss, resulting in shriveling; but edible coatings are supposed to control the water loss and therefore delay the phenomenon of weight loss in freshcut fruits [3]. Perez-Gago et al. [25] claimed that coating application did not reduce the weight loss in fresh-cut apples, probably due to the high relative humidity in the atmosphere of the packaged product. As shown in Figure 1(d), all samples demonstrated a gradual loss of weight during storage. The weight loss in uncoated orange slices was significantly greater than those of coated samples during regular storage period. The weight loss increased with time and the highest rate of weight loss was observed in the control sample (6.72\%). The least rates $(2.58 \%$ and $3.72 \%)$ were observed, respectively, in the samples coated with $100 \%$ and $50 \%$ Aloe vera. Consequently, the weight loss of orange slices coated with Aloe vera gel was significantly lower than other samples $(p<0.05)$. In this regard, the Aloe vera coating was more effective than green tea and black tea coatings. Similar results were obtained by Song et al. [14]. These authors reported that the weight loss increased during storage, but the weight loss of the Aloe vera gel-coated apple slices was significantly $(p<0.05)$ reduced after 8 days of storage compared to the control. The binding of Aloe vera gel molecules to the surface of apple slices might reduce the porosity of apple slices, resulting in lower water loss [14]. It is reported that Aloe vera gel reduces the respiration rate, ethylene production, weight loss, and therefore the softening of fresh-cut fruit textures [18].

Gelatin coatings show good barrier characteristics against oxygen and aroma transfers at low and intermediate relative humidity. However, they have poor barrier properties against water vapor transfer due to their hydrophilic nature [9]. Therefore, to modify the poor water vapor barrier properties of this protein film, a combined coating of gelatin with other substances may be used. 


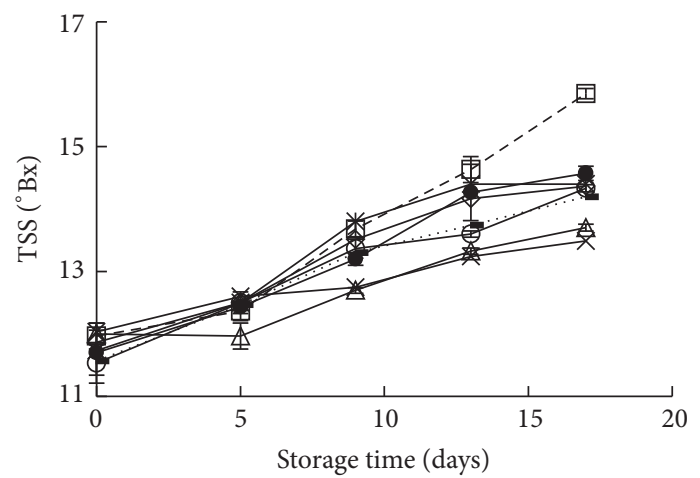

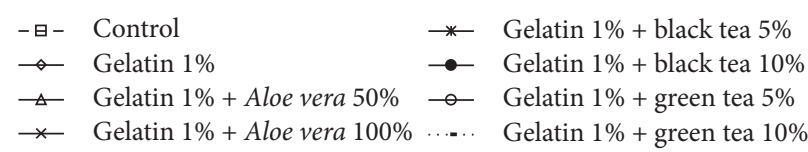

(a)

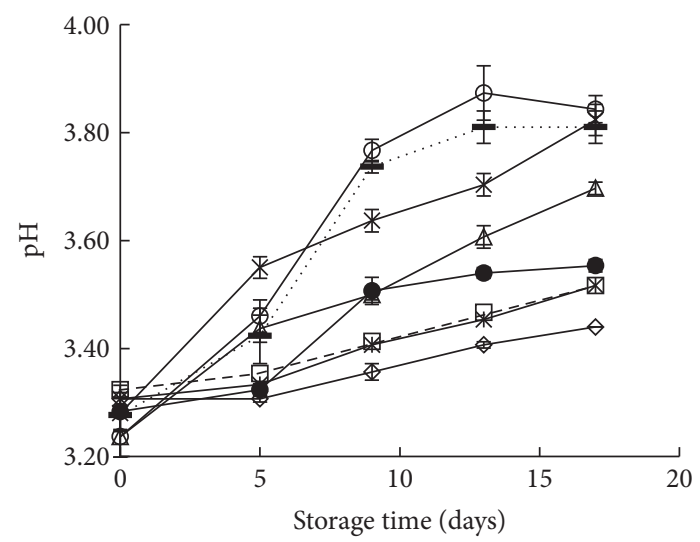

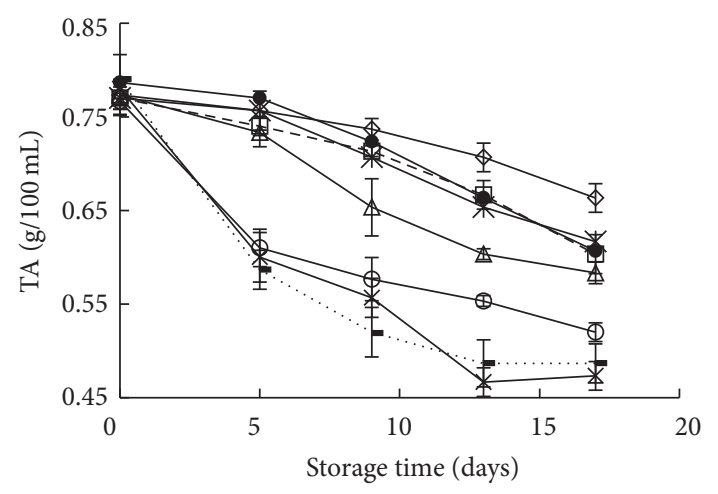

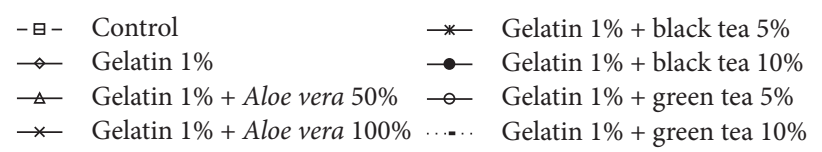

(b)

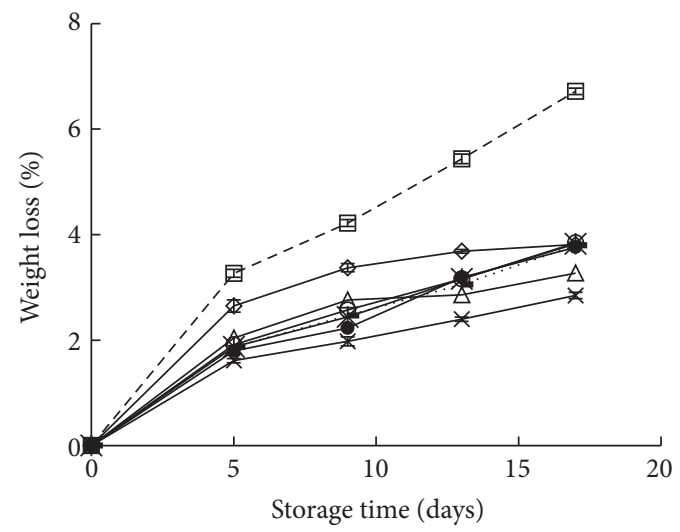

$\begin{array}{llll}-\bullet- & \text { Control } & * & \text { Gelatin } 1 \%+\text { black tea } 5 \% \\ \hookrightarrow & \text { Gelatin } 1 \% & - & \text { Gelatin } 1 \%+\text { black tea } 10 \% \\ \triangleleft & \text { Gelatin } 1 \%+\text { Aloe vera } 50 \% & - & \text { Gelatin } 1 \%+\text { green tea } 5 \% \\ \rightarrow & \text { Gelatin } 1 \%+\text { Aloe vera } 100 \% & \ldots . & \text { Gelatin } 1 \%+\text { green tea } 10 \%\end{array}$

(d)

(c)

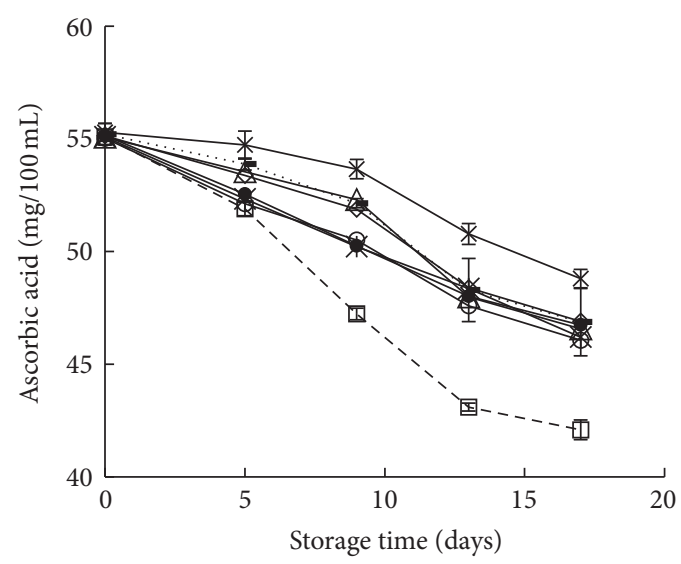

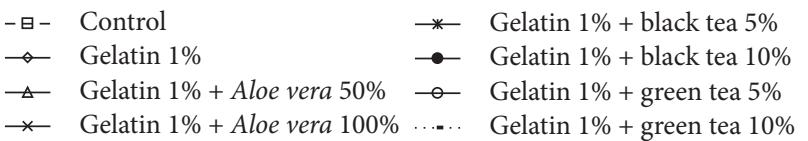

(e)

FIgURE 1: The variation of $\mathrm{pH}$, total soluble solid (TSS), titratable acidity (TA), weight loss, and ascorbic acid content of coated fresh-cut oranges during storage at $4^{\circ} \mathrm{C}$ for 17 days. Error bars represent standard deviation between replicates $(n=3)$. 
3.3. Ascorbic Acid Content. Although ascorbic acid is critical for the health, it should be noted that it is sensitive to processing and is unstable during storage period. Thus, this vitamin is often used as an indicator of the quality of fruits and vegetables in the distribution chain [26].

The ascorbic acid variations in fresh-cut oranges are shown in Figure 1(e). Statistical analysis showed that storage period at $4^{\circ} \mathrm{C}$ had a significant effect on the ascorbic acid content $(p<0.05)$. In terms of ascorbic acid content, a significant difference was observed among coated and control samples. The initial content of ascorbic acid in control sample $(55.1 \mathrm{mg} / 100 \mathrm{~mL}$ orange juice) reached $42.1 \mathrm{mg} / 100 \mathrm{~mL}$ after 17 days of storage at $4^{\circ} \mathrm{C}$, which had the highest reduction among different treatments; meanwhile the lowest reduction was found in the coated samples with $100 \%$ Aloe vera, in which their ascorbic acid contents reduced from $55.29 \mathrm{mg} / 100 \mathrm{~mL}$ to $48.80 \mathrm{mg} / 100 \mathrm{~mL}$ after 17 days of storage.

These results are in good agreement with those reported by other authors. In this regard, Plaza et al. [1] found significant reduction in ascorbic acid content (19-24\% for ascorbic acid and $15-23 \%$ for total vitamin C) of whole orange fruits, hand-peeled orange fruits, and manually separated slices during 12 days of cold storage. However, there were no significant differences between whole fruits, peeled fruits, or slices at the end of refrigerated storage. Del Caro et al. [27] also reported a significant reduction in ascorbic acid content of citrus fruits slices during storage at $4^{\circ} \mathrm{C}$ for 12 days. It should be noted that ascorbic acid is susceptible to degradation by enzymes (ascorbate oxidase or peroxidase), light, oxygen, heat, and peroxides [1]. Ascorbic acid is the antioxidant present in fruits and vegetables and usually is destroyed after processing [7]. The slicing of fruits and vegetables induces oxidative stress, which implies a role of ascorbic acid as antioxidant [26]. The L-ascorbic acid and its oxidation product, L-dehydroascorbic acid, are biologically active. Oxidation of ascorbic acid to dehydroascorbic acid can occur by reactive oxygen species [26]. In our study, higher levels of ascorbic acid in the coated sample than in control can be attributed to good barrier characteristics of gelatin against oxygen [9] and thus reduction of oxygen levels due to respiration [18].

Despite green tea extract, increasing Aloe vera concentration showed a protective effect on ascorbic acid content. This can be attributed to the low gas permeability of Aloe vera coating which inhibited the respiratory rate [28]. But increasing green tea concentration had no significant effect on the ascorbic acid content. However, Martín-Diana et al. [7] reported that increasing green tea concentration showed a protective effect due to the antioxidant capacity of catechins, avoiding ascorbic acid degradation.

3.4. Color Change. Color is an important factor in the perception of fresh-cut fruits' quality during their shelf life [25]. The oxidative degradation of ascorbic acid and nonenzymatic browning are reported as the major deteriorative reactions occurring during storage [29].

Figure 2 shows changes in the surface color of orange slices stored at $4^{\circ} \mathrm{C}$ for 17 days, as given by $L^{*}, a^{*}$, and $b^{*}$. Statistical analysis showed that $L^{*}$ (lightness/darkness), $a^{*}$ (redness/greenness), and $b^{*}$ (yellowness/blueness) color indices significantly changed during storage. The reduction trend of $L^{*}$ values in coated and uncoated samples occurred at different rates during the storage $(p<0.05)$, showing a darkening tendency in surface color of orange slices. $L^{*}$ value of samples was in the range of $48.19-48.50$ on the first day. The least reduction trend for $L^{*}$ was observed in the coated samples with 50 and $100 \%$ Aloe vera (11.07 and 8.72\%, resp.) in contrast to control, which had highest $L^{*}$ reduction $(28.48 \%) . L^{*}$ reduction during storage can be related to the occurrence of browning [7]. All of the coatings, especially Aloe vera coatings, significantly delayed the decrease of $L^{*}$ color parameter showing a clear effect on maintaining color attributes.

The color of orange slices in terms of CIE $a^{*}$ and $b^{*}$ values showed no significant $(p>0.05)$ differences between the coated and uncoated samples. In other words, no significant differences were observed between all treatments during the storage time. The initial values of $a^{*}$ and $b^{*}$ parameters were about 2.35 and 24.20 , which reached values ranging from 7.50 to 21.50 , respectively, at the end of storage period. In this regard, a significant increase in $a^{*}$ values and significant decrease in $b^{*}$ values were observed in all treatments during storage.

Color is a critical quality property of fresh-cut fruits, since slicing of fruits may often lead to enzymatic browning by polyphenol oxidases and peroxidases, which react with phenolic compounds and cause surface browning $[5,23]$.

The color of orange slices and juice can be affected by different mechanisms of nonenzymatic browning such as degradation of ascorbic acid, acid-catalyzed degradation of sugars, and Maillard reactions between reducing sugars and amino acids [29]. Also, oxygen and light affect the rate of carotenoid and ascorbic acid degradation. The decrease in $b^{*}$ (yellowness) of orange is contributed to carotenoids degradation [30]. Moreover, the ascorbic acid degradation can mainly be attributed to oxygen which increases the oxidative reactions and therefore the development of brown pigments. Subsequently, the color changes may occur as a result of brown pigments formation as well as the carotenoids degradation [29].

Martín-Diana et al. [7] reported that the browning levels of coated lettuce increased with green tea extract concentrations. In other words, increasing in green tea concentrations decreased $L^{*}$ values. The amount of polyphenols present in the green tea extracts might have favored quicker appearance of browning. As green tea is a rich source of polyphenols, it can act as a good substrate for browning-related enzymes [7]. It is reported that application of an Aloe vera gel coating is an effective method for maintaining the color of fresh-cut apple slices, as the Aloe vera gel coating can act as an oxygen barrier film, retarding the enzymatic browning. However, the coating does not completely prevent oxidative browning [14]. Siripatrawan and Harte [20] declared that adding green tea extract into chitosan film significantly affected $L^{*}, a^{*}$, and $b^{*}$ values of the film surface. Films without green tea extract had higher $L^{*}$ values, while with addition of green tea extract 

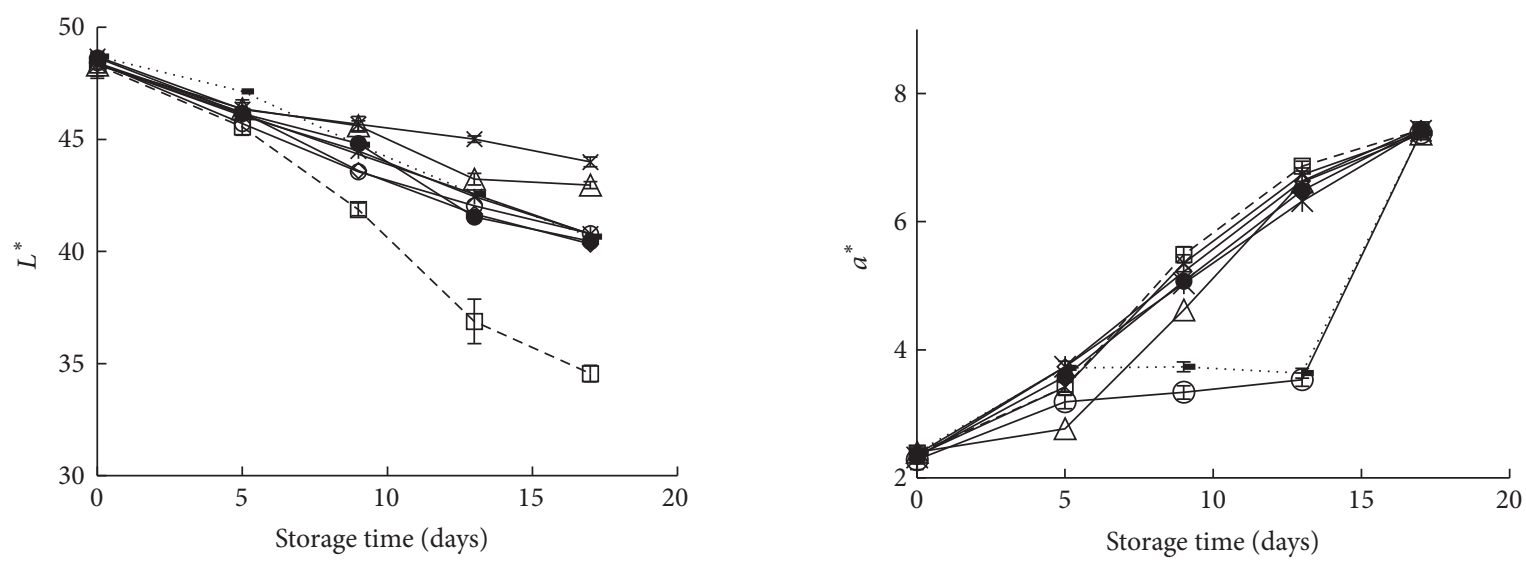

$\begin{array}{llll}- \text { - } & \text { Control } & \rightarrow & \text { Gelatin } 1 \%+\text { black tea } 5 \% \\ \rightarrow & \text { Gelatin } 1 \% & - & \text { Gelatin } 1 \%+\text { black tea } 10 \% \\ \triangle & \text { Gelatin } 1 \%+\text { Aloe vera } 50 \% & - & \text { Gelatin } 1 \%+\text { green tea } 5 \% \\ \rightarrow & \text { Gelatin } 1 \%+\text { Aloe vera } 100 \% & \cdots- & \text { Gelatin } 1 \%+\text { green tea } 10 \%\end{array}$

(a)

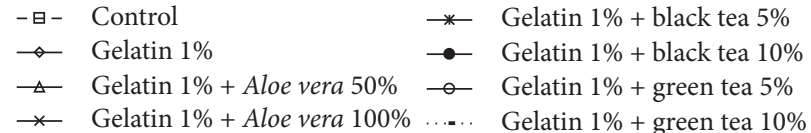

(b)
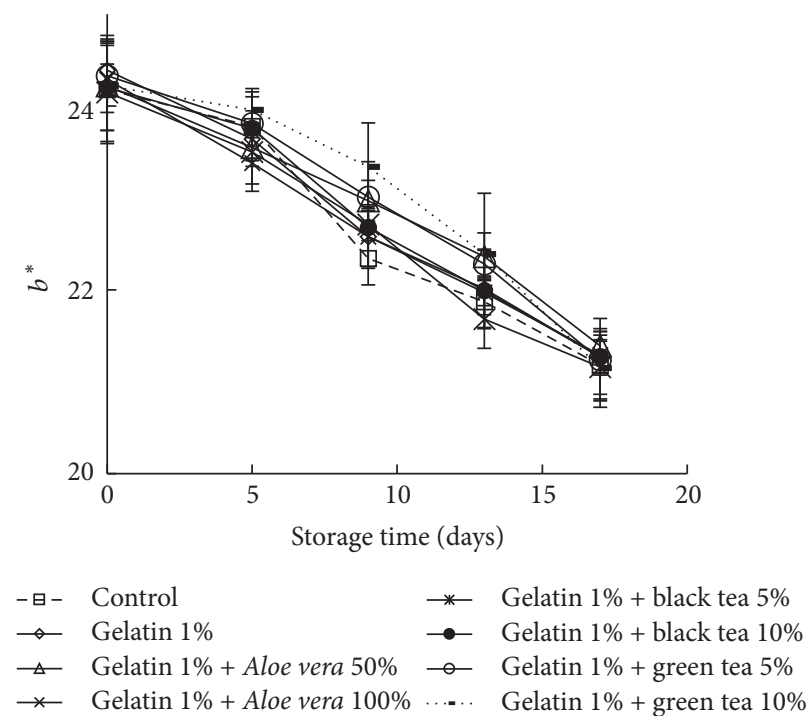

(c)

Figure 2: Color parameters $\left(L^{*}, a^{*}\right.$, and $\left.b^{*}\right)$ changes of coated fresh-cut oranges during storage at $4^{\circ} \mathrm{C}$ for 17 days. Error bars represent standard deviation between replicates $(n=3)$.

from 0 to $20 \%, L^{*}$ values decreased, while $a^{*}$ and $b^{*}$ values increased.

3.5. Microbial Analysis. The total viable counts in the fresh orange slices were $\sim 3.25 \log \mathrm{CFU} / \mathrm{g}$ for total aerobic mesophilic microorganisms and $\sim 2.20 \log \mathrm{CFU} / \mathrm{g}$ for yeast and mould. The total viable counts gradually and significantly increased with storage time in all treatments (Figure 3). The microbial population of coated sample with $1 \%$ gelatin was higher than other treatments (3.22 and $6.44 \log \mathrm{CFU} / \mathrm{g}$ at 0 and 17 days of storage, resp.), while samples coated with $10 \%$ green tea extract had the lowest microbial count compared to other treatments (3.27 and $4.17 \log$ CFU/g on day 0 and day 17 of storage period, resp.). Unexpectedly, the bacterial counts in slices coated with $1 \%$ gelatin were higher compared to control. Lower microbial population of samples coated with Aloe vera and green tea extracts is contributed to antimicrobial compounds of Aloe vera and green tea extracts $[6,18]$. In contrast, different concentrations of black tea had no effect on bacterial populations. Furthermore, there was no significant difference between samples treated with black tea and control samples $(p>0.05)$.

Similar results were obtained for fungi counts, whereas gelatin coating had the highest increase and green tea extracts had the lowest increase in fungal population of orange slices during storage. The fungi count had increased from $2.15 \log$ CFU/g to 7.16 and $7.60 \log$ CFU/g in control and samples treated with $1 \%$ gelatin, respectively, after 17 


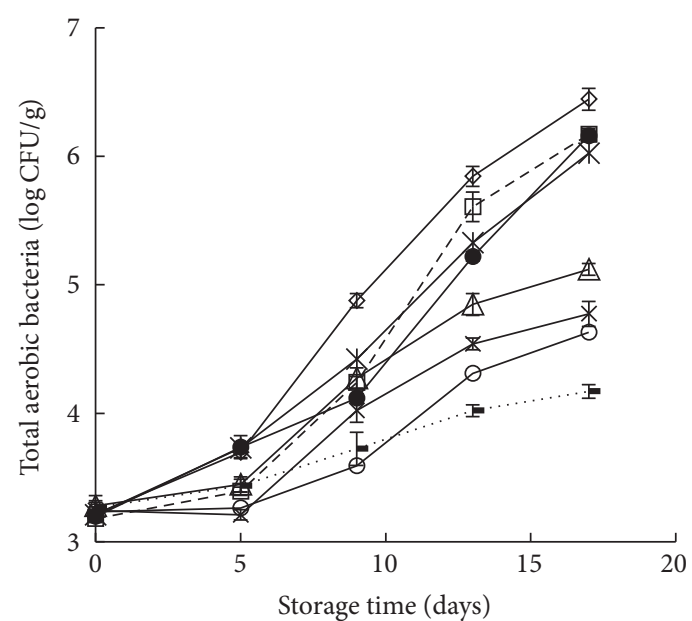

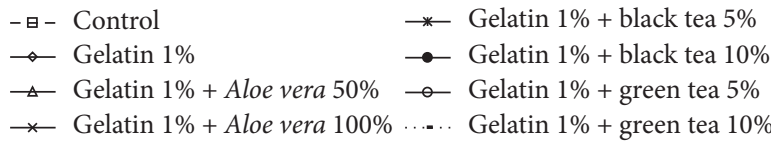

(a)

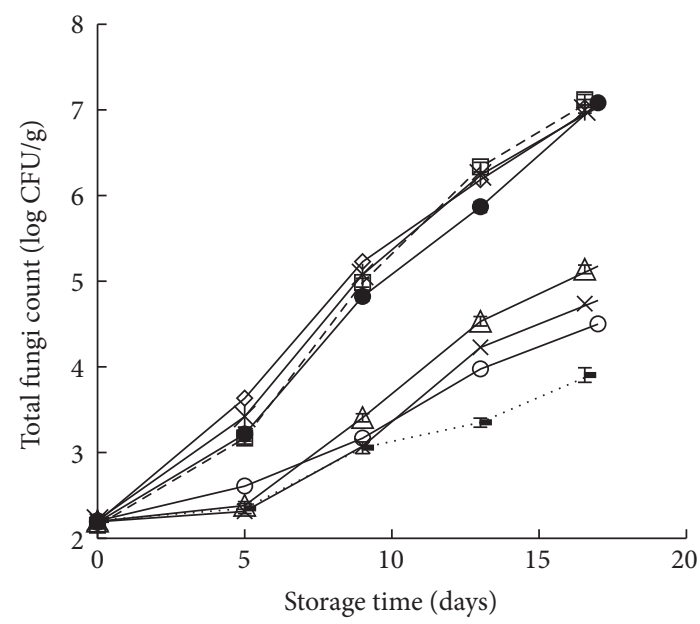

$\begin{array}{ll}\text { в - Control } & * \text { Gelatin } 1 \%+\text { black tea } 5 \% \\ \rightarrow \text { Gelatin } 1 \% & \rightarrow \text { Gelatin } 1 \%+\text { black tea } 10 \% \\ \triangleleft \text { Gelatin } 1 \%+\text { Aloe vera } 50 \% & - \text { Gelatin } 1 \%+\text { green tea } 5 \% \\ \rightarrow \text { Gelatin } 1 \%+\text { Aloe vera } 100 \% & \ldots \text {. Gelatin } 1 \%+\text { green tea } 10 \%\end{array}$

(b)

FIGURE 3: Total aerobic mesophilic bacteria and fungi counts of coated fresh-cut oranges during storage at $4^{\circ} \mathrm{C}$ for 17 days. Error bars represent standard deviation between replicates $(n=3)$.

days of storage at $4^{\circ} \mathrm{C}$, while the least increase in fungi population was observed in samples coated with $5 \%$ and $10 \%$ green tea extracts ( 4.50 and $3.94 \log \mathrm{CFU} / \mathrm{g}$, resp.). In addition, no significant differences were observed between black tea extracts and control sample $(p>0.05)$, indicating that black tea extract had no antifungal effects. It should be noted that Aloe vera and green tea extracts reduced the microbial population, and this effect was enhanced at higher concentrations of these extracts. In both cases, the inhibition of growth was a function of Aloe vera and green tea concentration.

The inhibition of microbial growth presented in this study was in good agreement with the antimicrobial effects of Aloe vera coating in table grape [16], sweet cherry [12], apple slices $[11,14]$, kiwifruit slices [17], and raspberry fruit [28] which showed a reduction of mesophilic aerobic bacteria as well as yeast and mould counts during storage.

Fresh-cut fruits are highly susceptible to pathogenic and spoilage microorganisms during the preparatory steps as a consequence of cross-contamination, the presence of a large area of cut surfaces and juices, and sugars leakage from damaged tissues [5]. The microbial growth on the surface of coated apple slices showed significant differences between the coated and uncoated samples, suggesting a biopreservative function of the edible coatings [11]. Aloe vera extract was reported to have antimicrobial functions, significantly reducing mesophilic bacteria, and to especially have antifungal activity $[12,16]$. Some individual components found in Aloe vera gel, such as saponins, acemannan, and anthraquinone derivatives, are known to have antibiotic activity and could be responsible for its antibacterial activity [16].

Green tea is a rich source of polyphenols (mainly catechins and catechin derivatives) that the antimicrobial activity of green tea has been attributed to these compounds $[6,7]$. Black tea is the product of complete fermentation. Fermentation of tea leaves causes a reduction in the concentration of catechins and their antimicrobial activities. In general, antimicrobial activity decreased when the extents of tea fermentation increased [31]. Matan et al. [6] confirmed the antimicrobial activity in green tea extract on freshcut dragon. The maximum yeast count of $6 \log \mathrm{CFU} / \mathrm{g}$ for nonthermal processed fruit is considered acceptable at any point of fruit product shelf life [4]. In this study, the yeast counts did exceed these levels for all samples at the end of storage, except for slices treated with Aloe vera and green tea extracts.

On the basis of our findings, the population of bacteria was less than fungi at the end of storage period. It should be noted that the susceptibility of bacteria to the antimicrobial effect of Aloe vera and green tea appears to increase with decrease in $\mathrm{pH}$ of the food [32], which is the case for orange with acidic $\mathrm{pH}$. Moreover, our results indicated that gelatin might accelerate microbial proliferation, as the microbial counts in the fruits treated with gelatin were even higher than control samples. This may be due to the fact that gelatin coating on orange slices is a source of protein with high water activity which can be utilized by microorganisms at the absence of antimicrobials present in tea and Aloe vera extracts and this layer is not present in control samples.

In the literature of fresh-cut fruits, the impact of microbial growth on TSS, AA, and $\mathrm{pH}$ has not been considered, and the discussions are focused on physicochemical changes. In this regard, microbial population might play an important role. Therefore, Pearson's correlation coefficient was used to establish the relationships between the microbial growth and some chemical parameters (Table 1). 
TABLE 1: Correlation coefficients between physicochemical and microbial quality parameters of orange slices stored at $4^{\circ} \mathrm{C}$ on day 17.

\begin{tabular}{|c|c|c|c|c|c|c|c|c|}
\hline & Days & $\mathrm{pH}$ & TA & TSS & AA & WL & TPC & TFC \\
\hline Days & 1.000 & $0.723^{* *}$ & $-0.239^{* *}$ & $0.728^{* *}$ & $0.849^{* *}$ & $-0.888^{* *}$ & $0.848^{* *}$ & $0.768^{* *}$ \\
\hline $\mathrm{PH}$ & $0.723^{* *}$ & 1.000 & $-0.225^{*}$ & $0.442^{* *}$ & $0.480^{* *}$ & $-0.536^{* *}$ & $0.304^{* *}$ & $0.228^{*}$ \\
\hline TA & $-0.239^{* *}$ & $-0.225^{*}$ & 1.000 & $-0.750^{* *}$ & $-0.486^{* *}$ & $0.185^{*}$ & -0.146 & 0.177 \\
\hline TSS & $0.728^{* *}$ & $0.442^{* *}$ & $-0.750^{* *}$ & 1.000 & $0.897^{* *}$ & $-0.726^{* *}$ & $0.686^{* *}$ & $0.464^{* *}$ \\
\hline $\mathrm{AA}$ & $-0.888^{* *}$ & $-0.536^{* *}$ & $0.185^{*}$ & $-0.726^{* *}$ & $-0.898^{* *}$ & 1.000 & $-0.833^{* *}$ & $-0.797^{* *}$ \\
\hline WL & $0.849^{* *}$ & $0.480^{* *}$ & $-0.486^{* *}$ & $0.897^{* *}$ & 1.000 & $-0.898^{* *}$ & $0.788^{* *}$ & $0.817^{* *}$ \\
\hline TFC & $0.768^{* *}$ & $0.228^{*}$ & 0.177 & $0.464^{* *}$ & $0.817^{* *}$ & $-0.797^{* *}$ & $0.920^{* *}$ & 1.000 \\
\hline TPC & $0.848^{* *}$ & $0.304^{* *}$ & -0.146 & $0.686^{* *}$ & $0.788^{* *}$ & $-0.833^{* *}$ & 1.000 & $0.920^{* *}$ \\
\hline
\end{tabular}

TA, titratable acidity; TSS, total soluble solids; AA, ascorbic acid; WL, weight loss; TPC, total plate count (aerobic mesophilic bacteria); TFC, total fungal count. $p<0.01$.

** Correlation is significant at the 0.01 level (2-tailed).

${ }^{*}$ Correlation is significant at the 0.05 level (2-tailed).

Interestingly, highly significant correlation coefficients $(p<0.01)$ were found between microbial counts, TSS, $\mathrm{pH}$, AA, and weight loss. Significant correlation coefficients were observed between microbial counts and TSS, suggesting that microbial growth strongly affects the solubilization of high molecular weight compounds. In general, microorganisms on fresh-cut products fall in the category of bacteria, yeasts, and moulds. As spoilage progresses, degradation of the high molecular weight plant polymers is later brought about by moulds and pectinolytic and cellulolytic bacteria. Fruit products undergo fermentative spoilage by lactic acid bacteria or yeasts, resulting in the production of acids, alcohol, and carbon dioxide and therefore higher TA and lower $\mathrm{pH}$ [33]. The higher acidity of control might result from its higher moisture evaporation and therefore higher TSS. In fact, the description of changes in physicochemical characteristics is complicated, mostly due to the microorganism growth on fruit slices.

3.6. Sensory Analysis. Fresh-like quality is an important aspect in terms of consumer satisfaction, which is attributed to the color, texture, taste, and aromatic properties of the product [17]. Twelve panelists (6 males and 6 females) were asked to assess the quality of orange slices stored at $4^{\circ} \mathrm{C}$ on days 1,9 , and 17 . Figure 4 shows the quality attribute scores (color, aroma, flavor, and overall acceptance) for the examined samples.

50 and $100 \%$ Aloe vera coated slices as well as control obtained the highest sensory scores from the viewpoint of color and aroma and flavor. But the lower scores were awarded by coated slices with green tea and black tea extracts. The color evaluation of orange slices showed a significant reduction over time, which was in consistency with the results of $L^{*}$ variations. Results showed that the overall acceptance of the orange slices was significantly reduced during storage. The highest overall acceptance was observed in 50 and 100\% Aloe vera samples followed by $10 \%$ green tea. The lowest score of overall acceptance was given to control. The control and coated samples with black tea extracts showed no significant differences in terms of color and overall acceptance $(p>$ 0.05). Except for green tea extract, with increasing Aloe vera and black tea extracts concentration, the panelists did not perceive any significant difference in sensorial quality at the end of storage period.

Therefore, the panelists gave greater sensory scores to aloe-coated orange slices compared to coated slices with gelatin and green tea and black tea extracts at the end of storage. Higher sensory quality of Aloe vera gel-coated apple slices compared to uncoated ones was also reported by Chauhan et al. [11] and Song et al. [14].

\section{Conclusion}

Edible coatings used in this study had considerable effects on some quality attributes of fresh-cut oranges. All of the gelatin-based coatings reduced weight loss, ascorbic acid degradation, and color darkening. Coatings containing green tea and Aloe vera extracts also preserved microbial quality, whereas green tea was more potent. Sensory characteristics were highly retained by Aloe vera coatings. The effects of black tea-incorporated coatings were comparable to gelatin coating and were not as effective as green tea and Aloe vera treatments. Finally, it can be concluded that gelatin coatings containing Aloe vera or green tea extracts have potential to maintain the quality and extend the shelf life of fresh-cut orange.

\section{Additional Points}

Practical Applications. Controlling the fresh quality and microbial growth is a challenging problem of fresh-cut fruit industry. Consequently, it is recommended to use edible coatings (natural polysaccharides, proteins, and antioxidants) to overcome the concerns of fresh-cut fruit storage. In recent years, Aloe vera gel and green tea extract have been used in different food types due to their health benefits. The growing use, their health benefits, easy acceptance by consumers, and their lower price in comparison with other substances incorporated in coating materials made us assess the potency of Aloe vera gel and green tea and black tea extracts for being used in coatings of fresh-cut oranges. In this regard, higher physicochemical and microbial qualities were achieved for 


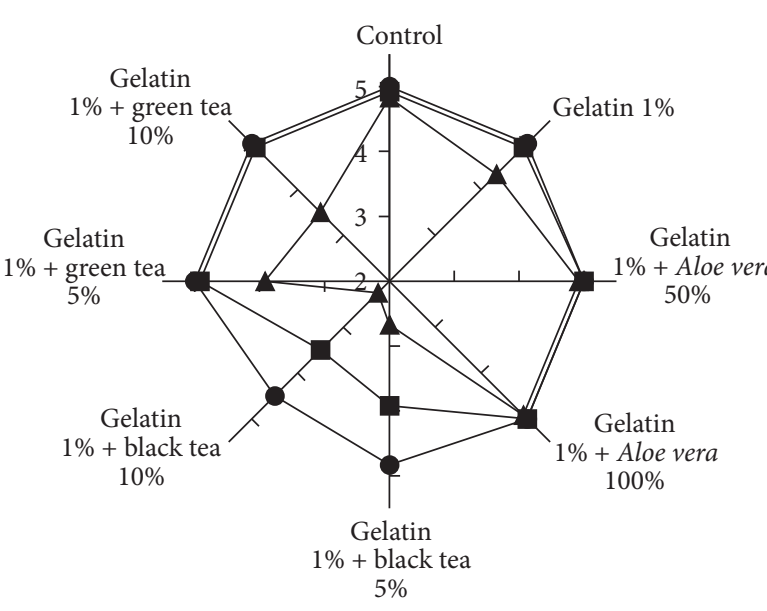

Aroma and flavor

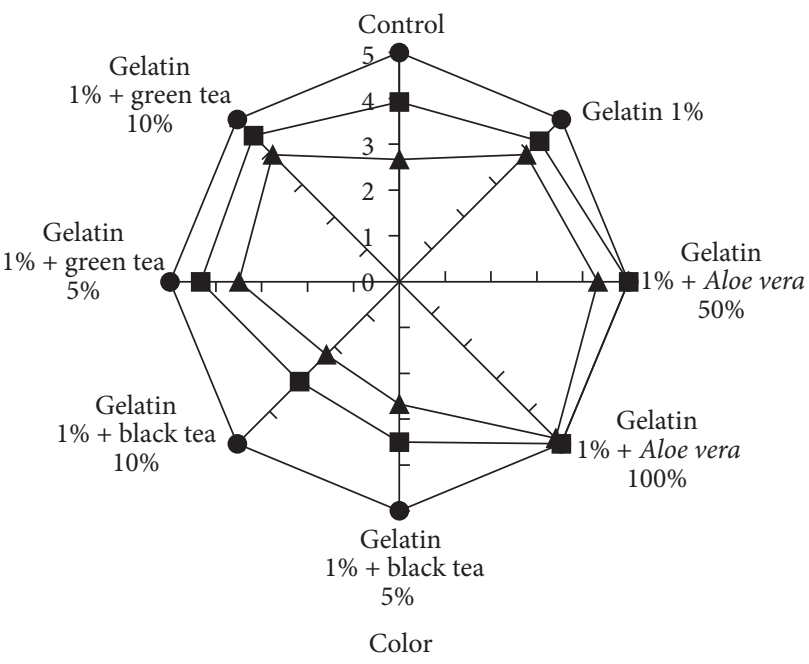

Color

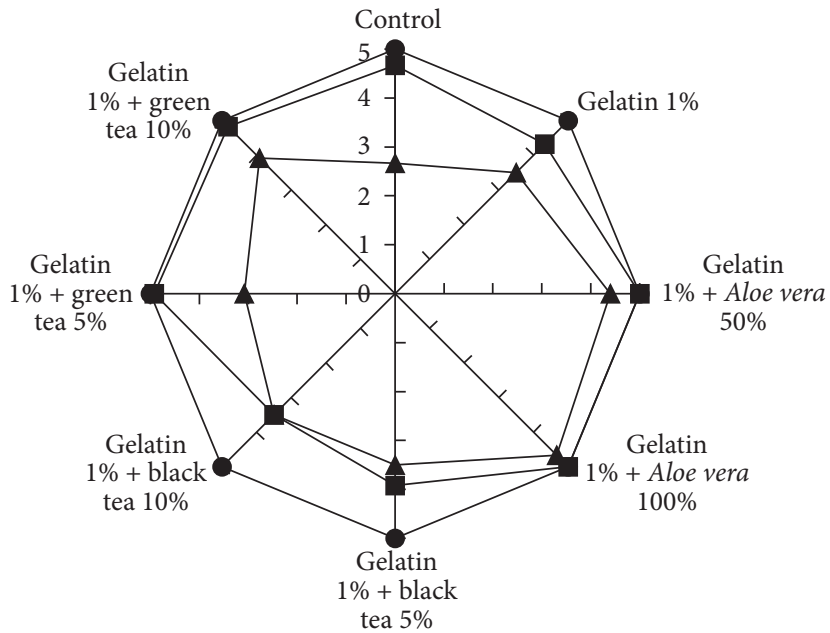

Overall acceptance

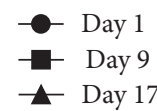

FIGURE 4: Sensory attributes of fresh-cut oranges on days 1, 9, and 17. Scoring system of color, aroma, flavor, and overall acceptance from extremely dislike (1) to extremely like (5).

samples coated with Aloe vera and green tea extracts. It seems that Aloe vera gel and green tea extract have the potency of being used as edible coating in food industry.

\section{Competing Interests}

The authors declare that there are no competing interests regarding the publication of this paper.

\section{Acknowledgments}

The authors would like to acknowledge Islamic Azad University, Yasooj Branch Research Council, for support of this work.

\section{References}

[1] L. Plaza, I. Crespo, S. de Pascual-Teresa et al., "Impact of minimal processing on orange bioactive compounds during refrigerated storage," Food Chemistry, vol. 124, no. 2, pp. 646651, 2011.

[2] P.-J. Chien and C.-C. Chou, "Antifungal activity of chitosan and its application to control post-harvest quality and fungal rotting of Tankan citrus fruit (Citrus tankan Hayata)," Journal of the Science of Food and Agriculture, vol. 86, no. 12, pp. 1964-1969, 2006.

[3] R. K. Dhall, "Advances in edible coatings for fresh fruits and vegetables: a review," Critical Reviews in Food Science and Nutrition, vol. 53, no. 5, pp. 435-450, 2013.

[4] M. A. Rojas-Graü, R. M. Raybaudi-Massilia, R. C. SolivaFortuny, R. J. Avena-Bustillos, T. H. McHugh, and O. MartínBelloso, "Apple puree-alginate edible coating as carrier of 
antimicrobial agents to prolong shelf-life of fresh-cut apples," Postharvest Biology and Technology, vol. 45, no. 2, pp. 254-264, 2007.

[5] G. Oms-Oliu, M. A. Rojas-Graü, L. A. González et al., "Recent approaches using chemical treatments to preserve quality of fresh-cut fruit: a review," Postharvest Biology and Technology, vol. 57, no. 3, pp. 139-148, 2010.

[6] N. Matan, K. Puangjinda, S. Phothisuwan, and M. Nisoa, "Combined antibacterial activity of green tea extract with atmospheric radio-frequency plasma against pathogens on fresh-cut dragon fruit," Food Control, vol. 50, pp. 291-296, 2015.

[7] A. B. Martín-Diana, D. Rico, and C. Barry-Ryan, "Green tea extract as a natural antioxidant to extend the shelf-life of freshcut lettuce," Innovative Food Science \& Emerging Technologies, vol. 9, no. 4, pp. 593-603, 2008.

[8] K. T. H. Dang, Z. Singh, and E. E. Swinny, "Edible coatings influence fruit ripening, quality, and aroma biosynthesis in mango fruit," Journal of Agricultural and Food Chemistry, vol. 56, no. 4, pp. 1361-1370, 2008.

[9] R. Andrade, O. Skurtys, F. Osorio, R. Zuluaga, P. Gañán, and C. Castro, "Wettability of gelatin coating formulations containing cellulose nanofibers on banana and eggplant epicarps," LWTFood Science and Technology, vol. 58, no. 1, pp. 158-165, 2014.

[10] M. D. Boudreau and F. A. Beland, "An evaluation of the biological and toxicological properties of Aloe barbadensis (Miller), Aloe vera," Journal of Environmental Science and Health, Part C, vol. 24, no. 1, pp. 103-154, 2006.

[11] O. P. Chauhan, P. S. Raju, A. Singh, and A. S. Bawa, "Shellac and aloe-gel-based surface coatings for maintaining keeping quality of apple slices," Food Chemistry, vol. 126, no. 3, pp. 961-966, 2011.

[12] D. Martínez-Romero, N. Alburquerque, J. M. Valverde et al., "Postharvest sweet cherry quality and safety maintenance by Aloe vera treatment: a new edible coating," Postharvest Biology and Technology, vol. 39, no. 1, pp. 93-100, 2006.

[13] M. J. Ahmed, Z. Singh, and A. S. Khan, "Postharvest Aloe vera gel-coating modulates fruit ripening and quality of 'Arctic Snow' nectarine kept in ambient and cold storage," International Journal of Food Science \& Technology, vol. 44, no. 5, pp. 10241033, 2009.

[14] H.-Y. Song, W.-S. Jo, N.-B. Song, S. C. Min, and K. B. Song, "Quality change of apple slices coated with aloe vera gel during storage," Journal of Food Science, vol. 78, no. 6, pp. C817-C822, 2013.

[15] S. L. Marpudi, L. S. S. Abirami, R. Pushkala, and N. Srividya, "Enhancement of storage life and quality maintenance of papaya fruits using Aloe vera based antimicrobial coating," Indian Journal of Biotechnology, vol. 10, no. 1, pp. 83-89, 2011.

[16] J. M. Valverde, D. Valero, D. Martínez-Romero, F. Guillén, S. Castillo, and M. Serrano, "Novel edible coating based on Aloe vera gel to maintain table grape quality and safety," Journal of Agricultural and Food Chemistry, vol. 53, no. 20, pp. 7807-7813, 2005.

[17] S. Benítez, I. Achaerandio, M. Pujolà, and F. Sepulcre, "Aloe vera as an alternative to traditional edible coatings used in fresh-cut fruits: a case of study with kiwifruit slices," LWT_-Food Science and Technology, vol. 61, no. 1, pp. 184-193, 2015.

[18] S. Benítez, I. Achaerandio, F. Sepulcre, and M. Pujolà, "Aloe vera based edible coatings improve the quality of minimally processed 'Hayward' kiwifruit," Postharvest Biology and Technology, vol. 81, pp. 29-36, 2013.

[19] D. Navarro, H. M. Díaz-Mula, F. Guillén et al., "Reduction of nectarine decay caused by Rhizopus stolonifer, Botrytis cinerea and Penicillium digitatum with Aloe vera gel alone or with the addition of thymol," International Journal of Food Microbiology, vol. 151, no. 2, pp. 241-246, 2011.

[20] U. Siripatrawan and B. R. Harte, "Physical properties and antioxidant activity of an active film from chitosan incorporated with green tea extract," Food Hydrocolloids, vol. 24, no. 8, pp. 770-775, 2010.

[21] K. L. Bett, D. A. Ingram, C. C. Grimm et al., "Flavor of freshcut Gala apples in barrier film packaging as affected by storage time," Journal of Food Quality, vol. 24, no. 2, pp. 141-156, 2001.

[22] R. A. Saftner, J. A. Abbott, A. A. Bhagwat, and B. T. Vinyard, "Quality measurement of intact and fresh-cut slices of Fuji, Granny Smith, Pink Lady, and GoldRush apples," Journal of Food Science, vol. 70, no. 5, pp. S317-S324, 2005.

[23] D. Albanese, L. Cinquanta, and M. Di Matteo, "Effects of an innovative dipping treatment on the cold storage of minimally processed Annurca apples," Food Chemistry, vol. 105, no. 3, pp. 1054-1060, 2007.

[24] G. I. Olivas, D. S. Mattinson, and G. V. Barbosa-Cánovas, "Alginate coatings for preservation of minimally processed 'Gala' apples,' Postharvest Biology and Technology, vol. 45, no. 1, pp. 89-96, 2007.

[25] M. B. Perez-Gago, M. Serra, and M. A. D. Río, "Color change of fresh-cut apples coated with whey protein concentrate-based edible coatings," Postharvest Biology and Technology, vol. 39, no. 1, pp. 84-92, 2006.

[26] G. Cocetta, V. Baldassarre, A. Spinardi, and A. Ferrante, "Effect of cutting on ascorbic acid oxidation and recycling in fresh-cut baby spinach (Spinacia oleracea L.) leaves," Postharvest Biology and Technology, vol. 88, pp. 8-16, 2014.

[27] A. Del Caro, A. Piga, V. Vacca, and M. Agabbio, "Changes of flavonoids, vitamin $\mathrm{C}$ and antioxidant capacity in minimally processed citrus segments and juices during storage," Food Chemistry, vol. 84, no. 1, pp. 99-105, 2004.

[28] H. Hassanpour, "Effect of Aloe vera gel coating on antioxidant capacity, antioxidant enzyme activities and decay in raspberry fruit," LWT-Food Science and Technology, vol. 60, no. 1, pp. 495-501, 2015.

[29] S. Wibowo, T. Grauwet, J. S. Santiago et al., "Quality changes of pasteurised orange juice during storage: a kinetic study of specific parameters and their relation to colour instability," Food Chemistry, vol. 187, pp. 140-151, 2015.

[30] V. K. Haugaard, C. J. Weber, B. Danielsen, and G. Bertelsen, "Quality changes in orange juice packed in materials based on polylactate," European Food Research and Technology, vol. 214, no. 5, pp. 423-428, 2002.

[31] M. P. Almajano, R. Carbó, J. A. L. Jiménez, and M. H. Gordon, "Antioxidant and antimicrobial activities of tea infusions," Food Chemistry, vol. 108, no. 1, pp. 55-63, 2008.

[32] P. N. Skandamis and G.-J. E. Nychas, "Development and evaluation of a model predicting the survival of Escherichia coli O157:H7 NCTC 12900 in homemade eggplant salad at various temperatures, pHs, and oregano essential oil concentrations," Applied and Environmental Microbiology, vol. 66, no. 4, pp. 1646-1653, 2000.

[33] O. Lamikanra, Fresh-Cut Fruits and Vegetables: Science, Technology, and Market, CRC Press, Boca Raton, Fla, USA, 2002. 

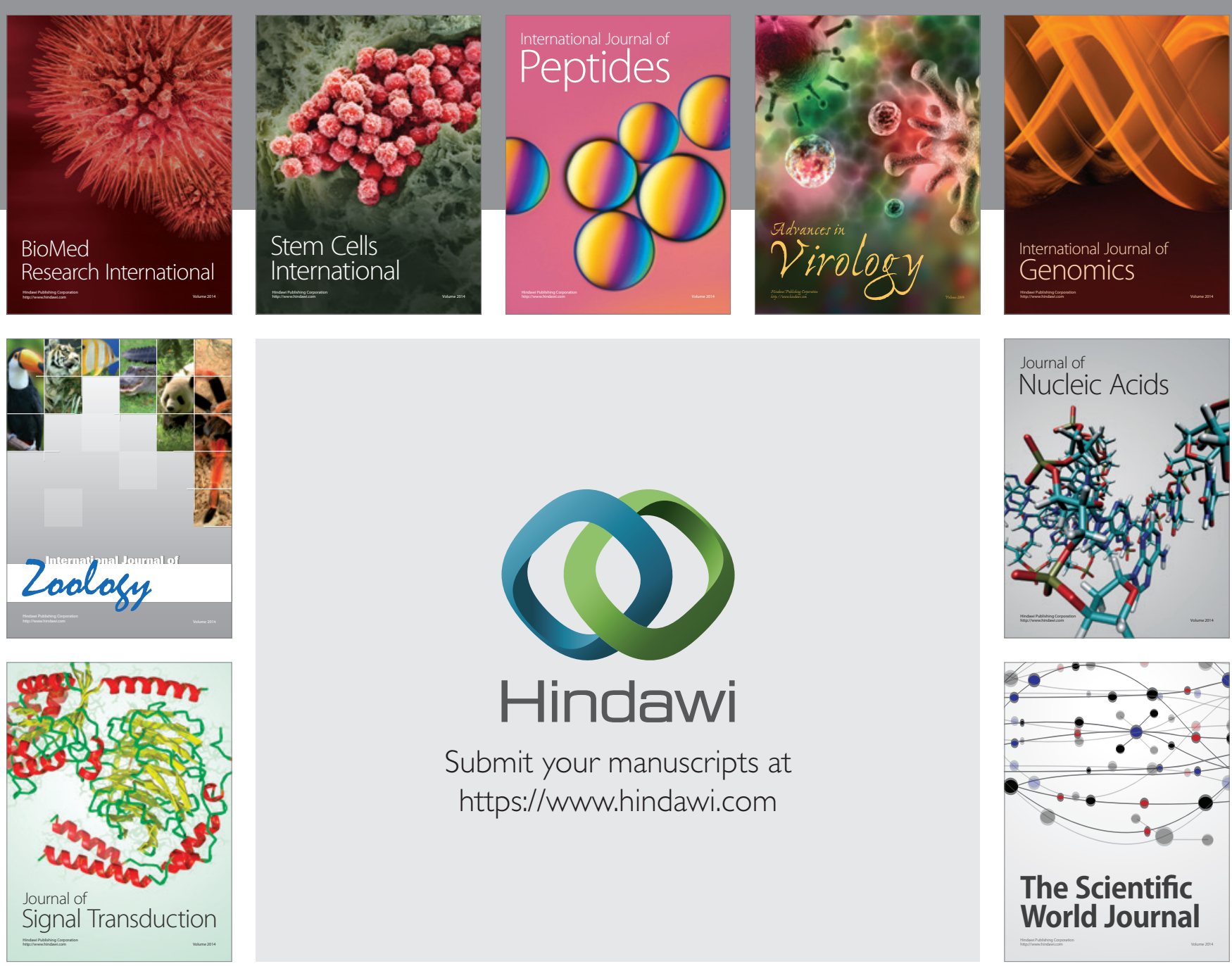

Submit your manuscripts at

https://www.hindawi.com
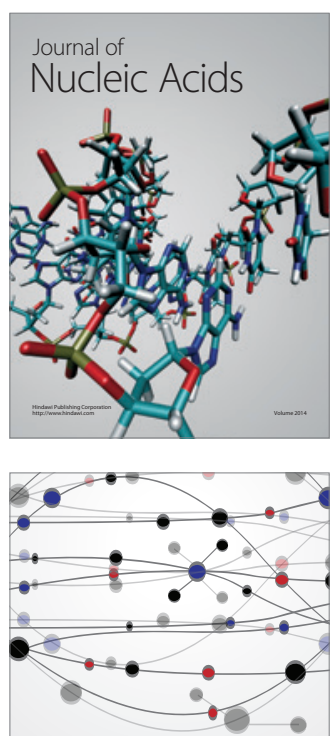

The Scientific World Journal
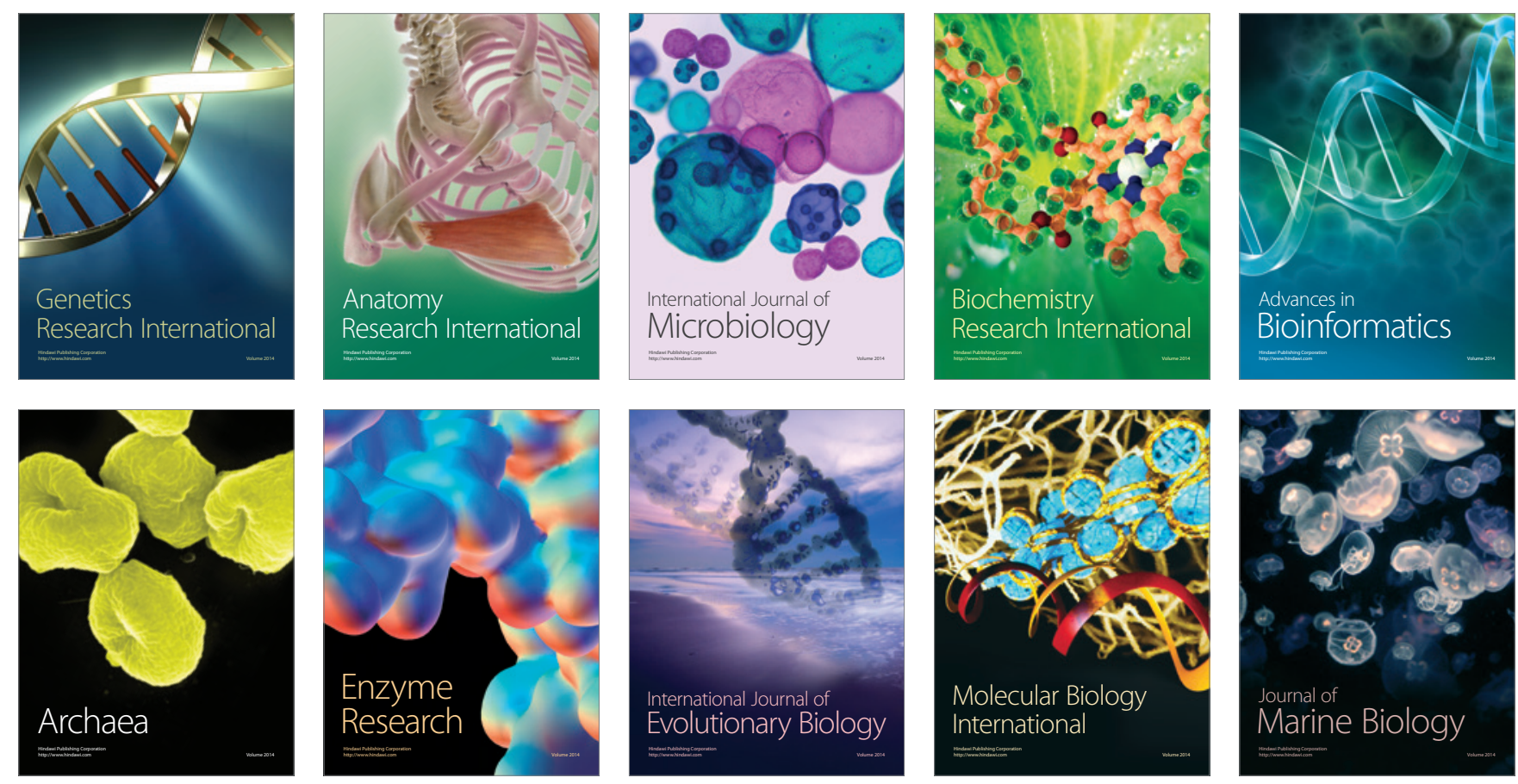